\title{
Editorial
}

\section{Biosolids Soil Application: Agronomic and Environmental Implications 2014}

\author{
Silvana Torri, ${ }^{1}$ Rodrigo Studart Corrêa, ${ }^{2}$ Giancarlo Renella, ${ }^{3}$ \\ Alejandro Vadecantos, ${ }^{4}$ and Leonid Perelomov ${ }^{5}$ \\ ${ }^{1}$ Cátedra de Química General e Inorgánica, Department of Natural Resources and Environment, School of Agriculture, \\ University of Buenos Aires, Avenida San Martín 4453, C1417DSE Buenos Aires, Argentina \\ ${ }^{2}$ University of Brasilia, Caixa Postal 04.401, 70910-970 Brasília, DF, Brazil \\ ${ }^{3}$ Department of Plant, Soil and Environmental Sciences, University of Florence, Piazzale delle Cascine 28, 50144 Florence, Italy \\ ${ }^{4}$ Centro de Estudios Ambientales del Mediterráneo (CEAM), C/Charles R. Darwin 14, Parque Tecnológico, 46980 Paterna, Spain \\ ${ }^{5}$ Department of Biology, Tula State University, Lenin Avenue 92, Tula 300012, Russia
}

Correspondence should be addressed to Silvana Torri; torri@agro.uba.ar

Received 11 March 2015; Accepted 11 March 2015

Copyright (C) 2015 Silvana Torri et al. This is an open access article distributed under the Creative Commons Attribution License, which permits unrestricted use, distribution, and reproduction in any medium, provided the original work is properly cited.

World production of biosolids is continuously increasing due to global urbanization of society and the increase in wastewater treatment coverage $[1,2]$. Nowadays, the accumulation of biosolids poses a growing environmental problem.

With the recent banning of ocean disposal and new stringent landfilling regulations, much more biosolids are now beneficially reused. Agriculture use of biosolids is still considered the main feasible disposal option, being both a cost-effective practice and a way to close the nutrient loop in agriculture and remediated soils. On the other hand, due to the ever increasing transportation, disposal costs, and increasing public pressure, efforts are being made to reduce the quantity of biosolids for disposal [3]. However, the demographic dynamics and technoeconomical problems in some developing countries lead to uncontrolled use of raw sewage in land application. This is mainly due to the fact that, in several areas around the world, increasing urbanization may lead to wastewater production in the order of $4.106 \mathrm{~L}$ per day, of which only a minor proportion can be effectively treated. Therefore, sewage systems often flow together with industrial effluents, enriching the biosolids with heavy metals, organic xenobiotics, endocrine disruptors, and hormones [4]. Land disposal of such material may cause detrimental effects on soil quality, crop production, and animal or human health.

In many countries, water shortages result in the use of treated municipal wastewater for agriculture irrigation.
Moreover, this practice is considered a valuable source for recycling and reuse of nutrients and water [5]. However, the use of sewage effluents for irrigation may cause soil pollution by the accumulation of hazardous elements [6] Consequently, there is a considerable interest in the effects of this practice on the quality of crops intended for human consumption.

S. Shanmugam and L. K. Abbott reviewed the potential for applying modified biosolids with soil amendments such as lime, clay, and biochar. The potential benefits of combining biosolids with other amendments can include reduction in microbial processes, leading to slow biosolids-borne nutrients. Co-application of biosolids with clay and biochar may lead to the retention of $\mathrm{N}$, decreasing $\mathrm{N}$ leaching through various mechanisms. Further investigation of the influence of amendments on modified biosolids products would enable a better understanding of soil nutrient cycling over the short and long term following its land application.

Progressive soil pollution with heavy metals also prevents the optimal use of other organic matter sources such as manure because this may increase soil metal mobility due to manure-induced soil alkalinisation. This can in turn increase metal solubilization and availability to crops caused by increased organic matter solubilization and soil salinity. The complex interplay of the environmental factors that can increase heavy metal toxicity was well illustrated by the work 
of A. R. A. Usman who shows how the increase of soil salinity values can increase the Cd toxicity to soil microorganisms in contaminated soils and its availability to crops such as barley.

$\mathrm{N}$ mineralization of bioresources was studied by S. W. Ives et al., who have incubated for 56 days at $12.5^{\circ} \mathrm{C}$ soils samples treated with anaerobically digested biosolids, limed biosolids, poppy seed waste, and poppy mulch. The bioresources have, respectively, released $25 \%, 45 \%, 36 \%$, and $8 \%$ of their total applied $\mathrm{N}$ as plant available nitrogen by the end of the incubation period. Mineralization rates were not related to bioresources $\mathrm{C}: \mathrm{N}$ ratios; the poppy mulch showed a significant negative priming effect over the incubation period. Based on $\mathrm{N}$ contents released through mineralization, the incorporation of bioresources in soils of temperate regions may not match crop $\mathrm{N}$ demands.

The effects of composted biosolids on foliar concentrations of N, P, and K in Salix miyabeana (SX 64) were studied by A. K. Quaye et al. The authors have found that composted biosolids increased soil P supply more than commercial fertilizer used as control and that foliar nutrient concentrations reached or even exceeded values reported for optimal growth of field grown Salix species. Foliar N and K concentrations were significantly higher at the beginning of the growing season but decreased as the season progressed. On the other hand, foliar P concentrations increased towards the end of the growing season. The significant effect of the organic amendment on soil P supply and its comparable effect on foliar concentration make composted biosolids a costeffective option relative to commercial fertilizers, besides the environmental benefits of land application of organic wastes.

S. Shanmugam and L. K. Abbott have investigated the residual effect of biosolids soil application $\left(50 \mathrm{tha}^{-1}\right)$ on ryegrass growth and on soil microbial biomass in a glasshouse experiment. Results have showed that the residual effect of biosolids on plant growth lasted for five ryegrass cycles. Soil microbial biomass $\mathrm{N}$ was not significantly influenced by biosolids application. The residual concentration of mineral $\mathrm{N}$ remaining in soil was also negligible and did not pose risk to the environment.

R. C. Nogueirol et al. have compared the effectiveness of three $\mathrm{P}$ extractants considering the (i) availability of $\mathrm{P}$ in soils amended with sewage sludge for 13 consecutive years and correspondent maize $\mathrm{P}$-uptake and (ii) availability of $\mathrm{P}$ in soils amended with a single application of sewage sludge and composted sewage sludge and correspondent sugarcane Puptake. They have found no significant correlations between $\mathrm{P}$ levels extracted from soils and $\mathrm{P}$ concentrations in diagnostic leaves. Resin extracted larger amounts of $\mathrm{P}$ in the short term experiment, while acidic extractants yielded larger amounts in the long-term experiment.

Another evidence of the fertilizer value of biosolids in agronomy is described in the work of L. A. J. Teixeira et al. The application of biosolids may release higher agronomic efficiency on fruit production of banana plants than the equivalent application rates of mineral fertilizers. These results suggest that other benefits beyond nutrient inputs, such as an improvement on soil physical properties, a slower release of nutrients through the mineralization of organic matter added with the sludge, and triggering of soil microbial activity, are taking place due to biosolids application.

In the paper "Surface-Applied Biosolids Enhance Soil Organic Carbon and Nitrogen Stocks but Have Contrasting Effects on Soil Physical Quality," mid- to long-term impacts of land-applied biosolids were studied by V. L. Jin. This study evaluates the effects of surface-broadcast biosolids application rate and duration on soil organic carbon stocks, soil aggregate stability, and selected soil hydraulic properties in a municipally operated, no-till forage production system. Total SOC stocks increased nonlinearly with application rate in perennial grass fields treated for 8 years with $0,20,40$, or $60 \mathrm{Mg}$ of Class B biosolids ha-1 yr-1 (midterm treatments). Soil organic $\mathrm{C}$ stocks in long-term treatment fields receiving 20 years of $20 \mathrm{Mgha}-1 \mathrm{yr}-1$ were $36 \%$ higher than those in midterm fields treated at the same rate. Surface-applied biosolids had contrasting effects on soil physical properties. Soil bulk density was little affected by biosolids applications, but applications were associated with decreased water-stable soil aggregates, increased soil water retention, and increased available water-holding capacity. This study contrasts the potential for $\mathrm{C}$ storage in soils treated with surface-applied biosolids with application effects on soil physical properties, underscoring the importance of site-specific management decisions for the beneficial reuse of biosolids in agricultural settings.

Silvana Torri
Rodrigo Studart Corrêa
Giancarlo Renella
Alejandro Vadecantos
Leonid Perelomov

\section{References}

[1] NWC, National Performance Report 2011-12: Urban Water Utilities, Australian Government-National Water Commission, 2013.

[2] D. Fytili and A. Zabaniotou, "Utilization of sewage sludge in EU application of old and new methods-a review," Renewable \& Sustainable Energy Reviews, vol. 12, no. 1, pp. 116-140, 2008.

[3] Y. Liu and J.-H. Tay, "Strategy for minimization of excess sludge production from the activated sludge process," Biotechnology Advances, vol. 19, no. 2, pp. 97-107, 2001.

[4] Y. Jin, N. Maleky, N. A. Kramer, and K. Ikehata, "Health effects associated with wastewater treatment, reuse, and disposal," Water Environment Research, vol. 85, no. 10, pp. 1954-1977, 2013.

[5] F. Pedrero, A. Allende, M. I. Gil, and J. J. Alarcón, "Soil chemical properties, leaf mineral status and crop production in a lemon tree orchard irrigated with two types of wastewater," Agricultural Water Management, vol. 109, pp. 54-60, 2012.

[6] N. Belaid, C. Neel, J. F. Lenain et al., "Assessment of metal accumulation in calcareous soil and forage crops subjected to long-term irrigation using treated wastewater: case of El HajebSfax, Tunisia," Agriculture, Ecosystems and Environment, vol. 158, pp. 83-93, 2012. 

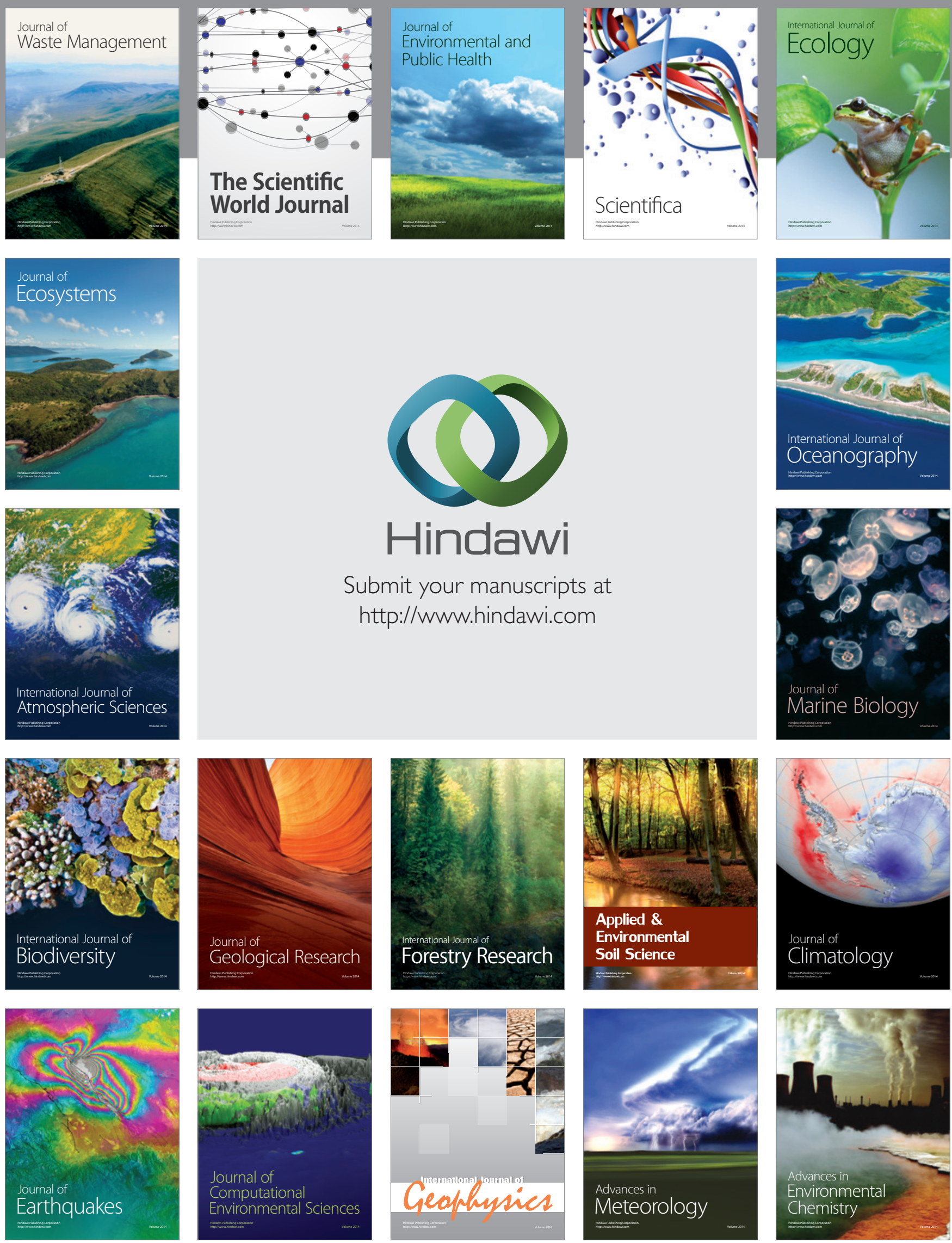